\title{
Transfer Pricing in a Multi-Product Environment
}

\author{
Savita A. Sahay ${ }^{1}$ \\ ${ }^{1}$ Rutgers Business School - Newark \& New Brunswick, Rutgers, The State University of New Jersey, 100, \\ Rockafeller Road, Rutgers University, Piscataway, NJ 08854-8054, USA \\ Correspondence: Savita A. Sahay, Rutgers Business School - Newark \& New Brunswick, Rutgers, The State \\ University of New Jersey, 100, Rockafeller Road, Rutgers University, Piscataway, NJ 08854-8054, USA. Tel: \\ 1-848-445-4369. Fax: (732) 445-3201. E-mail: ssahay@business.rutgers.edu
}

Received: October 11, 2014

Accepted: November 1, 2014

Online Published: November 2, 2014

doi:10.5430/afr.v3n4p132

URL: http://dx.doi.org/10.5430/afr.v3n4p132

\begin{abstract}
This paper develops a simple model of a decentralized multi-product firm in which transfer pricing is used to co-ordinate the activities of its constituent divisions. Two goods are produced in a single facility and the accounting system provides the full cost for each based on a rule in which overhead costs are allocated in proportion to direct labor costs. The study compares the performance of some commonly used transfer pricing (TP) policies with respect to level as well as efficiency of production. The policies studied are Actual Cost-Based TP (ACTP), Standard Cost-Based TP (SCTP), and a hybrid TP policy based on both standard and actual costs.

It is shown that under ACTP managers may have incentives to "pad" as well as misallocate costs deliberately to maximize their divisional incomes, while under SCTP there is over-reporting of costs leading to under-production. In general, neither policy achieves the first-best level of production or profit. ACTP yields higher profits to the firm than SCTP if the internally transferred good is the primary good produced by the firm. The hybrid policy eliminates some of the production inefficiencies associated with ACTP as well as the over-reporting problems associated with SCTP, resulting in a higher profit to the firm than can be achieved using either policy alone.
\end{abstract}

Keywords: Management accounting, Transfer pricing, Cost allocation, Goal congruence, Performance evaluation

\section{Introduction}

As firms grow in size and complexity, they tend towards a decentralized organization comprising several interacting divisions, typically organized as autonomous profit centers. (Note 1) In such cases, the central office faces the problem of ensuring goal congruence, i.e. of ensuring that divisional managers choose actions that are in the overall interests of the firm. This problem is especially difficult for vertically integrated firms in which one division provides goods or services to another. For performance measurement purposes, the value assessed for such internal transactions is called the transfer price. It appears as revenue in the income statement of the 'selling' division and as an expense in that of the 'buying' division. Since managers are typically evaluated and compensated based on the reported income of their divisions (Note 2), the method used for setting transfer prices also influences the decisions delegated to them.

The Transfer Pricing (TP) problem becomes even more complex when a division produces multiple goods and the common costs (also termed indirect costs, capacity costs or, more often, fixed costs) need to be divided among these goods. (Note 3) This process is referred to as cost allocation. (Note 4) Although managerial accounting textbooks as well as classical economists have long been pointing out that most allocation methods are overly simplistic, somewhat arbitrary and irrelevant for decision-making, there is widespread evidence that firms continue to allocate these costs. (Note 5) Interestingly, the literature emphasizes goal congruence and coordination as one of the main reasons why transfer prices are used and also why firms allocate overhead costs (Note 6). It is appropriate, therefore, to explore how the performance of a transfer pricing policy is affected by the choice of a particular cost allocation system. (Note 7)

This paper studies the problem of transfer pricing in a setting that includes cost allocation and in which autonomous divisional managers may have incentives to misallocate costs deliberately to maximize their divisional incomes. Using a simple model of a decentralized and diversified firm in which an upstream (selling) division produces multiple goods, some of which are transferred internally to a downstream (buying) division while others are sold externally in a perfectly competitive market, I analyze the interaction of cost allocation with transfer pricing policy 
and show that the resulting incentives created can significantly affect managers' decisions regarding the volume and efficiency of production that ultimately determine the firm's bottom line.

Since a cost allocation system primarily affects the full cost of each product line, I restrict attention to full cost-based TP policies. (Note 8) (Note 9) Most firms that engage in cost-based TP use either standard costs or actual costs as the basis for setting the transfer price. (Note 10) Accordingly, the TP schemes analyzed in this paper are standard cost-based TP (SCTP), actual cost-based TP (ACTP) and a hybrid scheme (HCTP) in which the transfer price is set to the minimum of standard and actual costs.

The term standard cost usually refers to a budgeted cost figure issued by the division responsible for producing the good (and hence, in the best position to estimate the production cost) before production is actually undertaken. The standard cost is used as the basis for making decisions about the quantity of goods to produce. Since a standard cost-based transfer price allocates the variance between standard and actual costs to the seller, it is expected that the seller will be motivated to keep actual costs down. To quote (Horngren, Datar and Foster, 2012): "[To] motivate the seller to produce efficiently, cost-based transfer prices should be based on budgeted rather than actual costs" (p. 870, original emphasis.)

Such thinking, however, is based on a static view of costs that ignores the dynamic influence that the selling division may have on the formation of both standard and realized costs. The setting of appropriate standards, in particular, is a problematic issue. Ideally, standards should be determined by detailed engineering studies at the production site, and should be reviewed at the appropriate level. In practice, however, the informational requirements of such an approach are too stringent and production managers - who are, after all, best informed about the cost environment often play a significant role in the standard-setting process. (Merchant, 1989) finds that profit center managers are often involved in setting and revising standards, and negotiate for budgets that are easier to meet. They like to forecast a pessimistic scenario even when they know better, especially when the information they provide is not easily verifiable. From their field study, Eccles and White (1988) conclude: "[by] setting standard costs he knew to be higher than what the actual costs would be, [the seller] ensured a positive variance [and] thereby contributed to the overall profitability of his division" (p. 28.)

Actual cost, in contrast, refers to a post-production cost figure. If only a firm produces only one good, the actual cost incurred is observable after production. For multi-product firms, the formula for computing the actual cost of producing a good is more complicated. It usually involves the allocation of costs that are part of the overall production process but that cannot be traced to individual products.

Foremost among such costs are manufacturing overhead costs such as power, indirect materials and labor, plant rent and insurance, property taxes and depreciation on plants, factory overhead costs and set-up and engineering costs. Manufacturing overheads are one of the most important cost categories in many companies. (Note 11) Other costs that need to be allocated among multiple goods are joint costs of a single production process that yields multiple products simultaneously. (Note 12)

There is little systematic evidence on the joint cost allocation methods that companies use, and a variety of innovative allocation methods have emerged recently in management accounting theory and practice (Note 13). However, the survey of (Hughes and Gjerde, 2003) estimates that 40 percent or more of firms rely on traditional allocation systems. (Horngren, Datar and Foster, 2012) state that "according to the most detailed study on joint cost allocation methods used by companies in the U.S., $62 \%$ of the companies use [direct] labor as the basis for allocating manufacturing overhead costs to products." Since direct labor hours are a separately observable production input, this traditional method makes minimum demands on a company's accounting system. Labor hours are the classic basis for allocation in a manufacturing environment in which labor provides the greatest amount of added value to the final product. Labor may also be appropriate for service industries in which the greatest portion of expense for the service is labor. Many costs such as depreciation and interest are directly related to time, for which labor hours is an appropriate driver. Similarly, many administrative overhead costs such as payroll are directly related to the elapsed time of work. Accordingly, in this paper I use the simplest and most common method of overhead cost allocation, the traditional single driver method based on direct labor hours.

Under any cost allocation system, a primary advantage of ACTP is that it is often the easiest to implement due to easy availability of the actual costs and relevant drivers from the accounting books. This policy is also attractive from an internal accounting perspective since it generates an income statement that eliminates intra-company profits (Note 14). On the negative side, however, it provides no incentive to the supplying division to reduce its costs by taking any efficiency-improving measures. Moreover, it provides incentives to the supplying division to not only misallocate costs amongst products, but also to choose a suboptimal production method. For example, a production 
manager might buy a machine rather than leasing it or he might hire a full-time employee instead of an hourly consultant, so that he can pass on some of the indirect cost, even though direct costs would be the more efficient choice from the firm's point of view.

In order to mitigate this problem, I analyze a third cost based policy in this paper - a hybrid cost based transfer price (HCTP) based on standard as well as actual costs. In practice, hybrid transfer prices may use any combination of TP methods. For example, a hybrid scheme may take into account both cost and market information or may use cost information as the lower bound and allow negotiation to decide the final transfer price. Since our model considers only cost based schemes, I will use a combination of standard and actual cost information, so that the positive features of both the schemes can be combined. In my hybrid scheme, the transfer price is set equal to the minimum of actual and standard cost.

The main result of my analysis is that in a multi-product setting ACTP outperforms SCTP. This is despite the fact that product diversification creates a simple and direct incentive for cost shifting (or padding) and cross-subsidization under ACTP. This result may be viewed as providing theoretical justification for the common use of ACTP in practice. Additional results in the model that broadly conform to observations from industry practice are mentioned below:

1. SCTP results in efficient production but over-reporting of standard costs.

2. ACTP can result in inefficient production of the internal good.

3. Standards reported in ACTP are never exaggerated and result in higher levels of production than in SCTP.

4. Standards are never reported lower than actual costs (except in the hybrid scheme.)

5. HCTP outperforms both SCTP and ACTP.

In ACTP, production may be inefficient (in terms of wastage incurred on labor) for either the good transferred internally within the firm or the good sold externally but not both; which (if any) good is produced inefficiently depends on the relative importance of the two goods to the firm. In all cases, however, the standard cost reported is always equal to the actual cost of production.

If the internally transferred good is the "primary" good (i.e. revenues from its sales are sufficiently high), there is no wastage of labor on the external good; whenever labor is wasted on the internal good, the same amount of labor is expended on it regardless of the production division's private information; the standard cost reported in this situation is always equal to the actual cost and is always lower than the standard cost reported in the corresponding situations in SCTP. Finally, gross profits to the firm are higher with ACTP than with SCTP, assuming a uniform distribution for the downstream division's private information.

This paper extends the literature in two significant directions. In recent years, several researchers have used theoretical settings to compare two TP policies and studied how one of them performs relative to the other in the presence of specific economic factors. In my previous papers, I have compared the performance of some commonly used TP policies using a setting with incomplete contracts. (Note 15) In (Baldenius, Reichelstein and Sahay, 1999), a comparison of negotiated transfer pricing (NTP) and standard cost-based transfer pricing (SCTP) reveals general superiority of NTP. A second paper (Sahay, 2003) shows that the performance of actual cost-based transfer pricing with an additive markup is superior to any other cost-based policy in its class. In (Sahay, 2013), the actual cost-based method is shown to outperform several cost-based transfer pricing schemes, including SCTP. (Dikolli and Vaysman, 2006) compare negotiated and standard cost-based TP in a model that studies the impact of information technology. (Lengsfeld, Pfeiffer and Schiller, 2006) have attempted to compare actual cost-based TP with two standard cost-based schemes using cost of information gathering as the main deciding factor. (Pfeiffer, Schiller and Wagner, 2011) compare the performance of some cost-based transfer pricing policies in an asymmetric information setting and show that the superiority of one method over another depends on the degree of ex ante cost uncertainty. (Matsui, 2012) compares the performance of full cost and variable cost based transfer pricing and shows the superiority of full cost based method under certainty.

However, the above results are limited to the extent that the problem is studied in the context of a firm that makes only one product, and so has a simple costing system. In reality, most large firms produce many products and have complex systems that determine the cost of any product line. It is, therefore, more realistic to study the problem of transfer pricing in a firm that produces multiple products. The question is particularly interesting for cost-based transfer pricing because the true cost of a product or service is difficult to establish in a multi-product firm and a proxy for the true cost must be used in any cost-based TP scheme. (Note 16) This provides opportunity to a 
divisional manager to "shift" cost between products. In particular, it is possible that the manager will try to assign a higher portion of the total indirect costs to the intermediate good (since he will get reimbursed for it) so that his cost for the other products remains lean and he can show a higher total profit for his division, even if this cost shifting harms the overall firm profit. Hence, it is not clear that actual cost-based method can still outperform standard cost based transfer pricing, as it does in the single-product setting of (Sahay, 2013).

This study also makes a contribution to cost allocation literature. Early work on overhead cost allocation has pointed to several theoretical arguments for the design of overhead cost allocation systems (Note 17), but its affect on choice of a transfer pricing policy has never been studied. One exception is a study by (Rossing and Rohde, 2010), which examines how overhead cost allocation system design is affected by transfer pricing tax regulation. However, it seeks to explain the choice of an allocation system given a TP policy, rather than the choice of a TP policy, given an allocation system. Moreover, it is a case study conducted in a multinational enterprise where the TP policy's goal is tax compliance.

My work also builds on a range of studies that have examined the role of cost allocation mechanisms in guiding intra-firm resource allocation; papers in this category include (Zimmerman, 1979), (Baiman and Noel, 1985), (Balakrishnan et al., 2002), (Rajan, 1992), (Pfaff, 1994) and (Wei, 2004), among others. These studies have focused on cross-sectional cost allocations in a one-period setting. There has also been plenty of theoretical research on several aspects of cost allocation, but the literature has largely focused on deriving 'optimal' cost allocation schemes (Note 18).

The model developed here differs on three important aspects from the above literature. First, I do not assume that the agent's private information can be communicated to the principal. Hence, unlike the assumption in the above-mentioned papers, the revelation principle does not apply. Second, rather than searching for a theoretically optimal mechanism of cost allocation, I use a more modest framework that assumes that the cost allocation scheme is already in place. Finally, using a scenario in which a firm produces several goods, I study the tradeoffs faced by the upper management in instituting some of the popular transfer pricing methods, taking the pragmatic view that a multi-product environment in a decentralized firm will suit some TP policies more than others.

The rest of the paper is organized as follows: Section 2 describes the basic model, including all features of the firm's operation that are independent of the particular TP policies that will be analyzed; Section 3 describes the three candidate TP schemes, Sections 4 through 6 describe the major results obtained for each of the TP policies studied; Section 7 makes some concluding remarks.

\section{The Basic Model}

Consider a decentralized firm consisting of headquarters (HQ) and two divisions, marketing (Division 1 ) and production (Division 2). Each division operates under the control of a manager employed by HQ. Each division's manager is assumed to have some private information about his environment so that it is infeasible for headquarters to make production decisions on its own. The production division can produce one unit of each of two goods, Good 1 and Good 2. Good 1 is the primary good for the firm; it is a specialized good that is produced specifically for internal transfer to Division 1 for further processing and sale, while Good 2 is sold directly by Division 2 in an external market. It is assumed that Division 1 cannot source its input externally and must rely on Division 2 to produce Good 1. Whether or not Good $j$ is produced is decided by Division $j$ in accordance with the procedure described in the next section.

There are certain costs of production that must be borne by the production division regardless of the number of goods produced. These can be viewed either as manufacturing overhead costs or as joint costs of a single production process that yields multiple products simultaneously. We assume that the total manufacturing overhead is a fixed dollar amount $M$ known to all parties (Note 19).

In addition to the manufacturing overhead, production of either good requires the employment of labor. The minimum number of labor hours needed for producing Good 2 is denoted by $L_{2}^{*}$ and is common knowledge. However, the minimum number of labor hours required for producing Good 1 depends on Division 2's private information $\theta_{2}$. This minimum, $L_{1}\left(\theta_{2}\right)$ is given by:

$$
L_{1}\left(\theta_{2}\right)=L_{1}^{*}+\theta_{2}
$$

where $L_{1}^{*}$ is the amount of labor required for production of Good 1 by the "best type" of production manager $\left(\theta_{2}=0\right) . \quad \theta_{2}^{*}$ is a random variable with density function $f_{2}($.$) and corresponding distribution function F_{2}($.$) . The$ 
realized value of the random variable is Division 2's private information and is assumed to be unknown to other parties.

For the sake of simplicity, I regard labor costs as variable and manufacturing overhead costs as fixed. Note that there is no technological constraint regarding interaction of variable and fixed costs. There is only a feasibility constraint that stipulates a minimum amount of labor that must be supplied for each good. The production manager is free to "waste" labor on either (or both) goods if it serves his interest.

We assume that the labor market is perfectly competitive, and that each hour of labor costs $p$. Thus, if the goods are produced with $L_{1}$ and $L_{2}$ hours of labor respectively, the total cost of producing both the goods (charged against Division 2's divisional income) is:

$$
C=p\left(L_{1}+L_{2}\right)+M
$$

As mentioned earlier, Good $j$ is sold by Division $j$ in its own market. The revenue from the sale of Good 2 is denoted by $R_{2}^{*}$ and, like $L_{2}^{*}$ is easily observable. We assume that $R_{2}^{*}$ is large enough to cover the variable cost of producing Good 2 but not so large as to cover the entire fixed cost:

$$
p L_{2}^{\sim} \leq R_{2}^{\uparrow} \leq p L_{2}^{\uparrow}+M
$$

Thus, Good 2 is a secondary good, the production of which becomes a profitable possibility for Division 2 only when the primary good, Good 1 is being produced. (Note 20)

The revenue generated from the sale of Good 1 (net of Division l's processing costs) depends on the marketing manager's private information $\theta_{1} \in\left[0, \theta_{1}^{\max }\right] . \theta_{1}$ is a random variable whose realized value is known only to the marketing manager; other parties know only its density and distribution functions, $f_{1}($.$) and F_{1}($.$) . We assume that$ the inverse hazard rate $F_{1}(.) / f_{1}($.$) is increasing in \theta_{1}$. The revenue from the sale of Good 1 (net of Division l's processing costs), denoted $R_{1}\left(\theta_{1}\right)$ is given by:

$$
R_{1}\left(\theta_{1}\right)=R_{1}^{*}-\theta_{1}
$$

where $R_{1}^{*}$ is the revenue generated by the "best type" of marketing manager $\left(\theta_{1}=0\right)$.

Let $R_{1}$ denote the revenue from the sale of Good 1, net of Division 1's processing costs, and $R_{2}$ denote the revenue from the sale of Good 2. If a transfer price of $T$ is assessed for the transfer of Good 1, the divisional incomes for the two divisions are given by:

$$
\begin{aligned}
& I_{1}=R_{1}-T \\
& I_{2}=R_{2}-C+T
\end{aligned}
$$

Since a transfer price is an accounting charge or credit against divisional income, incentive properties of a transfer pricing policy can only be studied in a scenario where managerial compensation is based on divisional income. Accordingly, we assume that managerial compensation is an increasing function of divisional income, and each manager's objective is to maximize the income of his division.

\section{Standard Cost-based TP}

A pure standard cost-based transfer pricing policy (SCTP) is implemented in this model by the following sequence of events:

Date1

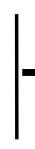

HQ announces TP policy
Date2

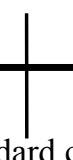
reported by seller
Date 3

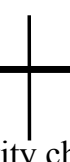

buyer
Date 4

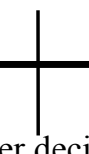

produce Good 2
Date 5

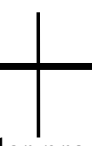

Seller produces goods
Date 6

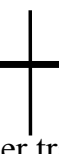

Seller transfers internal good
Date 7

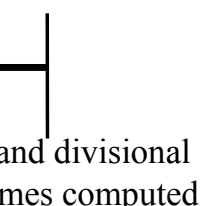

At Date 1, HQ announces the transfer pricing policy that will be used by the firm. This policy specifies that the standard cost reported by Division 2 (at Date 2) will be used as the transfer price for the intermediate good in computing divisional income (at Date 7). At Date 1, the two managers also observe their private information $\theta_{1}$ and $\theta_{2}$. 
At Date 2, Division 2 issues a standard cost figure $S$ as the cost of the internal good. At Date 3, Division 1 decides whether or not to place an order for Good 1 taking into account the standard cost reported earlier. At Date 4, Division 2 decides whether to produce Good 2; if either good is produced, the production division incurs the overhead $M$. At Date 5, Division 2 produces the goods, making production decisions $L_{j}$. At Date 6, Division 2 transfers Good 1 , the goods are sold and revenues realized. Finally, at Date 7, divisional incomes are computed using $T=S$.

It is clear that this policy gives the seller monopoly power in setting the transfer price. This might appear to be an extreme assumption but there is substantial evidence from practice that production managers often have such discretion in the setting of standard costs. (Note 21)

It should also be noted that in my time-line, the seller reports his standard after all uncertainty about actual production costs has been resolved. In practice, actual costs will usually be subject to random fluctuations even after standards have been set; the seller will just have to 'live with' the standards set earlier. This feature could be incorporated into the model by decomposing $\theta_{2}$ into two components, one of which is revealed only after the standard has been quoted. The results would not be qualitatively affected by this refinement.

To analyze the inefficiency resulting from the seller's monopoly power, I show first that Good 2 will be produced only if the order for Good 1 is received, and that production for both goods will be efficient. Also, naturally, Good 1 will be ordered if and only if the buyer's revenue $R_{1}\left(\theta_{1}\right)$ exceeds $S$. Thus, the standard reported at Step 2 will be chosen to solve:

$$
\max _{S} \operatorname{Pr}[\text { Sale } \mid S]\left(R_{2}^{*}+S-M-p\left(L_{1}^{*}+\theta_{2}+L_{2}^{*}\right)\right)
$$

where $\operatorname{Pr}[$ Sale $\mid S]$ denotes the probability with which the production manager expects the order to be placed for Good 1 if he were to quote a standard cost of $S$. Note that the seller's decision above incorporates efficient production decisions that he will take at Step 5. My first result follows from the maximization of his objective function.

\section{Proposition 1. SCTP results in under-production.}

Proof: All proofs are provided in the appendix to this paper.

We see here a manifestation of the 'deadweight' loss of potential trade associated with monopolistic price-setting. Thus, my model captures precisely the main problems with standard cost-based transfer pricing: the seller takes advantage of the unverifiability of standards by incorporating "slack" and overstates his cost. Trade is inefficient because the transfer price is set too high compared to the actual cost.

\section{Actual Cost-based TP}

ACTP is implemented in this model using the labor driver allocation method for allocating fixed cost. The labor driver allocation method is based on the assumption that the number of labor hours used for each good can be observed individually. The total cost $C$ of producing both goods is also observable and the actual cost incurred for the production of Good $l$ is set as:

$$
A_{1}=\frac{L_{1}}{L_{1}+L_{2}} C
$$

or equivalently,

$$
A_{1}=\frac{L_{1}}{L_{1}+L_{2}} M+p L_{1}
$$

Of course, the fixed cost needs to be allocated only if both goods are produced; if only one good is produced, its actual cost of production equals $M$ plus the cost of labor incurred in production.

The following sequence of events implements an actual cost based TP policy:
Date1
Date2
Date 3
Date 4
Date 5
Date 6
Date 7

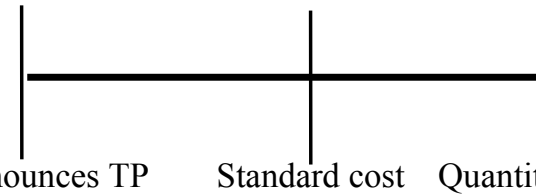

policy

reported by seller

buyer

Seller decides to produce Good 2

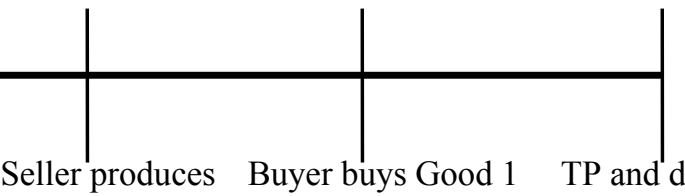

Seller produces Buyer buys Good 1 TP and divisional goods if $A_{1}<\mathrm{S} \quad$ incomes computed 
This is identical to the time-line of Section 4 except that at Date 6, the marketing division has an extra option - if the actual cost of the internal good $A_{1}$ exceeds $S$, the buyer may refuse to buy it even if an order had been placed at Step 3. If Division 1 decides to buy it, the production division transfers Good 1 , both the goods are sold and revenues realized. If Division 1 had placed the order and decides not to buy, Division 2 sells Good 1 at a "scrap" price (assumed, without loss of generality, to be zero.) At Step 7, divisional incomes are computed using $T=A_{1}$.

Similar to (2.3) we need an additional assumption in order to ensure that whenever the internal good is ordered, the external good will also be produced. To see this, suppose the internal good is ordered at Step 3. If the external good is not produced, the divisional income for Division 2 will be zero since the transfer price exactly offsets the actual cost of producing Good 1 . On the other hand, if the external good is produced, its divisional income will be $R_{2}^{*}-A_{2}$. Unless this income is positive, Division 2 will never produce the external good at all, thus removing the necessity for allocating the fixed cost altogether. Hence, we make the following "break-even" assumption:

$$
R_{2}^{*}-p L_{2}^{*} \geq M \frac{L_{2}^{*}}{L_{1}^{*}+L_{2}^{*}}
$$

which states that the contribution margin from (efficient) production of the external good exceeds its fixed cost allocation.

From expression (4.1) it is clear that the seller, who has control of the number of labor hours used in production, can shift costs from one good to another. The incentive for such cross-subsidization is quite simple - by wasting hours in the production of the internal good, Division 2 increases the allocation of fixed overhead to that good, leaving more of a surplus towards his divisional income.

To counterbalance this incentive, Division 1 is given the power to refuse the trade if the actual cost (or transfer price) is too high relative to the initially reported standard. As it turns out, however, Division 2 reports standards accurately, including in it any wastage of labor that it may choose to incur. This is captured in my second result:

Proposition 2. In ACTP the standard cost report is exactly equal to the actual cost of producing the internal good.

This result is based on two arguments. On the one hand, beating the standard cost is not beneficial for the seller, since letting the actual cost of the internally transferred good "eat up the slack" increases his divisional income by a like amount. On the other, quoting a standard cost lower than the eventual actual cost is self-defeating: he would receive the order from a larger range of buying division types, but these orders would eventually be canceled leaving the seller worse off than if he hadn't received the order in the first place.

While Proposition 2 establishes that the standard cost reported in ACTP is accurate, it does not preclude "cost-padding". The incentive for padding is inherent in the labor driver allocation method, because of which the seller is motivated to shift overhead costs to the internal good, thereby increasing his profit from the sale of the external one. To analyze this cross-subsidization, we start with the following definition:

Definition. For an arbitrary but fixed value $v$ of $A_{1}$ the iso- $A_{1}$ curve for $v$ is

the locus of all feasible points $\left(L_{1}, L_{2}\right)$ that satisfy $v=p L_{1}+M L_{1} /\left(L_{1}+L_{2}\right)$.

Differentiating the defining equation of the curve, we find:

$$
\frac{d L_{2}}{d L_{1}}=\frac{L_{2}}{L_{1}}+\frac{p}{M L_{1}}\left(L_{1}+L_{2}\right)^{2}
$$

from which it follows that iso- $A_{1}$ curves are always increasing. Also, since $A_{2}=v L_{2} / L_{1}$ along the curve, the seller would prefer to minimize the ratio $L_{2} / L_{1}$. It is possible to show that if the seller wishes to induce a particular value $v$ of $A_{1}$, his choice of the labor inputs $L_{1}$ and $L_{2}$ must be unique. This optimal combination is found by moving towards the left on the iso- $A_{1}$ curve for $v$ until further movement becomes infeasible, as illustrated graphically in Figure 1 below. 


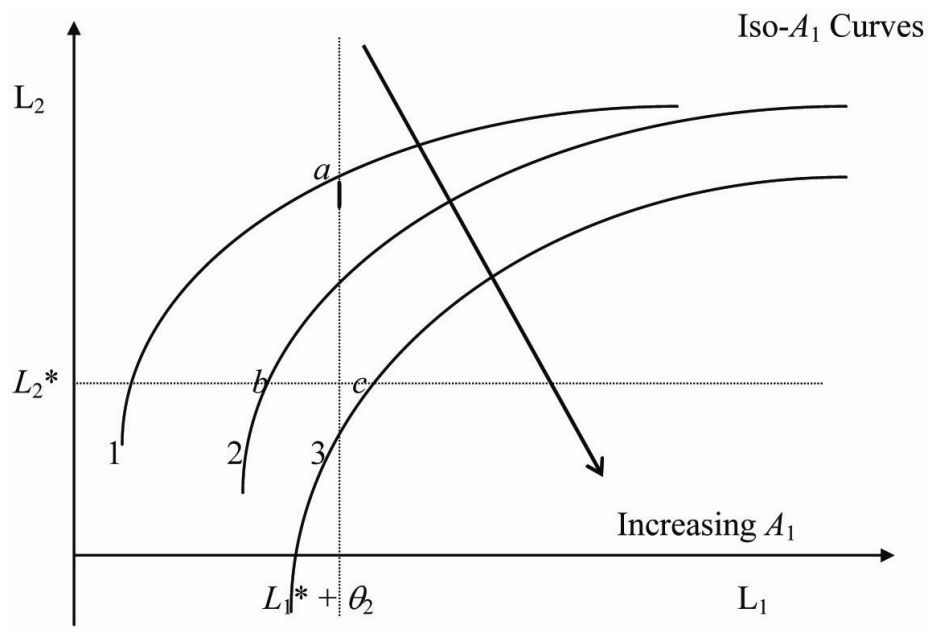

Figure 1. Iso- $A_{1}$ Curves

The figure shows three iso- $A_{1}$ curves. Each is increasing in $L_{1}$ and along each one, the optimal choice for Division 2 is to minimize $L_{1}$. In other words, the seller will move towards the left along the iso- $A_{1}$ curve until the vertical dotted line (the minimum possible value of $L_{1}$ ) is reached. Of course, the value of $A_{1}$ along the curve could be such that the horizontal dotted line (minimum possible value of $L_{2}$ ) is reached before the vertical one as we move leftward along the curve. (See the curve numbered 3 which meets the horizontal dotted line at point $c$ at which $L_{1}>L_{1}^{*}+\theta_{2}$ ). For such cases, choosing $L_{1}=L_{1}^{*}+\theta_{2}$ renders $L_{2}$ infeasible, and the optimal decision becomes $L_{2}=L_{2}^{*}$.

The analysis so far shows that it is never in the production manager's interest to waste both $L_{1}$ and $L_{2}$. We can therefore restrict the solution of ACTP to the L-shaped frontier of the feasible region demarcated by the horizontal line $L_{2}=L_{2}^{*}$ and the vertical line $L_{1}=L_{1}^{*}+\theta_{2}$.

The option of wasting $L_{2}$ may appear counter-intuitive at first glance, since it can only reduce the profit to Division 2 from its external market. Note, however, that it reduces $A_{1}$ thus making internal trade more likely. If there is a large profit to be made from the external market, it might be worthwhile to waste $L_{2}$, thereby reducing some of these profits, to gain the benefit of increased internal trade. We will make the following assumption that eliminates this problematic possibility, and is also in harmony with our view of the internal good as the primary good:

$$
\frac{F_{1}}{f_{1}}\left(R_{1}^{*}-p\left(L_{1}^{*}+\theta_{2}\right)-M \frac{L_{1}^{*}+\theta_{2}}{L_{1}^{*}+\theta_{2}+L_{2}^{*}}\right) \geq R_{2}^{*}-p L_{2}^{*}-M \frac{L_{2}^{*}}{L_{1}^{*}+\theta_{2}+L_{2}^{*}}
$$

Since $F_{1} / f_{1}$ is an increasing function, this assumption can be interpreted as requiring that $R_{1}^{*}$ be "large enough". In other words, having fixed all the other parameters of the model, one can always find a value of $R_{1}^{*}$ beyond which this assumption will be true.

We are now in a position to compare SCTP and ACTP.

Proposition 3. For all types $L_{2}$ the standard reported in ACTP is lower than that reported in SCTP.

Given that the standard reported in ACTP is always lower than that reported in SCTP, and given that production is requested in either situation under identical circumstances (viz. $\theta_{1} \leq R_{1}^{*}-S$ ), it might be expected that the benefit to the firm as a whole is greater in ACTP than in SCTP. However, we must still account for the fact that labor is wasted in ACTP for a range of production manager types, making it necessary to compare the benefits of increased production with the losses due to inefficient production.

This comparison is facilitated by observing that the gross profit to the firm in each case is given by the expected value of $R_{1}+R_{2}^{*}-M-p\left(L_{1}+L_{2}\right)$, the expectation being taken over the region of $\left(L_{1}, L_{2}\right)$ space over which production occurs. In order to show that ACTP outperforms SCTP, we note first that when production is efficient, ACTP yields higher expected profits because it induces production from a larger range of types of the marketing manager (by Proposition 3.) Thus, we need only show that ACTP performance is superior for the production manager types that waste labor on the internal good. 
Proposition 4: ACTP outperforms SCTP if revenue for the internal good is distributed uniformly.

\section{The Hybrid Scheme}

In this section, we devise a TP scheme that combines features of both SCTP and ACTP. One of the main problems with SCTP is that it creates incentives for the manager to misrepresent his expected cost by inflating the standard. This is because any variance between actual and standard production cost flows straight to the production manager's bottom-line. Given that the actual cost of production is revealed by the accounting system, it makes sense for management to use this information ex post in order to mitigate the incentive problem. In particular, HQ might try to devise a hybrid scheme that penalizes the production division in case of a high variance between standard and actual cost figures.

Accordingly, we modify the SCTP scheme of Section 4 as follows: the TP policy announced by HQ at Date 1 stipulates that if the actual production cost of the transferred good turns out to be lower than the standard cost reported at Date 2, then the transfer price will be set equal to the actual cost rather than the standard cost. In other words, the transfer price formula is:

$$
T=\min \left\{A_{1}, S\right\}
$$

We are able to show that this hybrid scheme is better than either of the pure schemes.

Proposition 5: A TP policy which sets the TP to the minimum of SC and AC will outperform a pure SC based TP as well as a pure $A C$ based TP.

\section{Conclusion}

This paper is the first attempt at the marriage of two incorrigibles: cost allocation in a multiproduct firm and TP policy, which may provide an opportunity to waste as well as misallocate costs. Firm characteristics relevant to TP choice that are embodied in the model include diversity (whether the firm is a single-product or multi-product firm), information asymmetry (whether a division's manager has private information that is not shared by headquarters or by other managers,) moral hazard (whether managers' choices can be observed and contracted upon) and degree of integration (whether the firm allows outsourcing of intermediate products).

Some of the results of this paper agree with the conventional wisdom regarding cost-based TP schemes while others offer new insights into empirically observed phenomena. For example, standard cost-based TP has long been recognized as resulting in exaggerated cost reports and under-production; this is shown to be true in our model as well. On the other hand, the common use of full actual cost-based TP in the industry has been something of a mystery to theoreticians dealing with transfer pricing (see Kaplan and Atkinson (89)). It is held that this policy provides no incentives to production managers to produce efficiently or make cost reducing improvements.

This paper shows that a multi-product setting creates a simple and direct model for ACTP, and shows that ACTP can, in fact, outperforms SCTP even if there are inefficiencies. In ACTP production may be inefficient for either the good transferred internally within the firm or the good sold externally but not both; which (if any) good is produced inefficiently depends on the relative importance of the two goods to the firm. If the internally transferred good is the "primary" good (i.e. capable of earning much higher revenue than the external good), there may be wastage of labor in its production. However, the standard cost reported in this situation is always equal to the actual cost and is always lower than the standard cost reported in the corresponding situations in SCTP. This makes for a higher level of production, which compensates for the production inefficiencies.

Thus, the paper provides a simple explanation for a widely observed and important empirical phenomenon for which little theoretical justification has been previously put forward. While the primary focus of this research is to identify economic factors that make ACTP preferable to SCTP and vice versa, the paper suggests that using both standard and actual costs can be preferable to using either alone.

In an extension of this work, it will be interesting to compare alternative cost allocation methods, such as activity based costing $(\mathrm{ABC})$ and resource consumption accounting (RCA) to see if the choice of transfer pricing policy changes and how the incentives for cost padding and shifting might be different.

\section{References}

Baiman, S., Evans, J. H., \& Noel, J. (1987). Optimal contracts with a utility-maximizing auditor. Journal of Accounting Research, 217-244. http://dx.doi.org/10.2307/2491016

Balakrishnan, R. \& Sivaramakrishnan K. (2002). A critical overview of the use of full-cost data for planning and pricing, Journal of Management Accounting Research, 14, 3-31. http://dx.doi.org/10.2308/jmar.2002.14.1.3 
Baldenius, T. (2000), Intrafirm trade, bargaining power and specific investments, Review of Accounting Studies, 5, 27-56. http://dx.doi.org/10.1023/A:1009612901910

Baldenius, T. (2003). Delegated investment decisions and private benefits of control, The Accounting Review, 78, 909-930. http://dx.doi.org/10.2308/accr.2003.78.4.909

— Reichelstein, S., \& Sahay, S. (1999). Negotiated versus Cost-Based Transfer Pricing, Review of Accounting Studies, 4, 67-91. http://dx.doi.org/10.1023/A:1009646505439

— Dutta, S. \& Reichelstein, S. (2007). Cost allocation for capital budgeting decisions, The Accounting Review, vol.82, pp.837-867. http://dx.doi.org/10.2308/accr.2007.82.4.837

Datar, S. \& Rajan, M. (2014). Managerial Accounting: Making decisions and motivating performance, first Ed. Pearson.

Dikolli, S. \& Vaysman, I. (2006). Information technology, organizational design, and transfer pricing, Journal of Accounting and Economics. 41, 1-2, 201-234. http://dx.doi.org/10.1016/j.jacceco.2005.06.001

Eccles, R. (1985). The Transfer Pricing Problem: A Theory for Practice, Lexington Books, Lexington.

Eccles, R. \& White, H. (1988), Price and Authority in Inter-Profit Center Transactions. American Journal of Sociology. 94, S17-S48. http://dx.doi.org/10.1086/228941

Edlin, A. \& Reichelstein, S. (1995). Specific Investment under Negotiated Transfer Pricing: An Efficiency Result, The Accounting Review, 70, 2.

Ernst \& Young. (2005, 2007-2008). Global surveys. Global Transfer Pricing Trends, Practices and Analysis.

Govindarajan, V., \& Anthony, R. N. (1982). Use of Cost Data in Pricing Decisions. College of Administrative Science, Ohio State University.

Holmstrom, B. \& Tirole, J. (1991). Transfer Pricing and Organizational Form, Journal of Law, Economics and Organization, 7, 201-228.

Horngren, C. T., Sundem, G. L., \& Stratton, W. O. (2012). Introduction to Management Accounting. New Delhi, India: Prentice- Hall.

Kaplan, Robert S., \& Anthony A. Atkinson. (1998). Advanced management accounting. Vol. 3. Upper Saddle River, NJ: Prentice Hall.

Lengsfeld, Stephan, Thomas Pfeiffer, \& Ulf Schiller. (2006). Centralized versus decentralized transfer pricing and cost-system choice. Available at SSRN 925170.

Matsui, Kenji (2012). Cost-based transfer pricing under R\&D risk aversion in an integrated supply chain, International Journal of Production Economics, 139, 1, 69-79. http://dx.doi.org/10.1016/j.ijpe.2011.10.030

Merchant, K. (1989). Rewarding Results: Motivating Profit Center Managers, Harvard Business School Press.

Miller, J. \& T. Vollman. (1985). The Hidden Factory. Harvard Business Review: 142-150.

Pfaff, D. (1994). On the allocation of overhead costs. European Accounting Review, 3(1), 49-70. http://dx.doi.org/10.1080/09638189400000003

Pfeiffer, T., Schiller, U., \& Wagner, J. (2011). Cost-based transfer pricing. Review of Accounting Studies, 16(2), 219-246. http://dx.doi.org/10.1007/s11142-011-9140-0

Rajan, M. (1992). Cost allocations in multi-agent settings, The Accounting Review, 67, 527-545.

Rajan, M. V., \& Reichelstein, S. (2009). Depreciation rules and the relation between marginal and historical cost. Journal of Accounting Research, 47(3), 823-865. http://dx.doi.org/10.1111/j.1475-679X.2009.00334.x

Reece, James S., \& William R. Cool. (1978): "Measuring investment center performance." Harvard Business Review 56.328.

Rogerson, W. (1997). Inter-temporal cost allocation and managerial investment incentives, Journal of Political Economy, vol.105, pp. 770-795. http://dx.doi.org/10.1086/262093

(2008). Inter-temporal cost allocation and investment decisions, Journal of Political Economy, 116, 931-950. http://dx.doi.org/10.1086/591909

Rossing C \& Rohde, C. (2010). Overhead cost allocation changes in a transfer pricing tax compliant multinational enterprise, Management Accounting Research, 21, 199-216. http://dx.doi.org/10.1016/j.mar.2010.01.002 
Sahay, S. (2003). Transfer Pricing based on Actual Cost, Journal of Management Accounting Research, 15, 177-192. http://dx.doi.org/10.2308/jmar.2003.15.1.177

Sahay, S. (2013), A Comparison of Negotiated and Actual Cost-Based Transfer Pricing, Working paper, Rutgers University.

Shelanski, H. (1994), Transfer Pricing and the Organization of Internal Exchange, Unpublished dissertation, University of California, Berkeley.

Shim, E., \& Sudit, E. F. (1995). How manufacturers price products. MANAGEMENT ACCOUNTING-NEW YORK-, 76, 37-37.

Tang, R. (1992). Transfer Pricing in the 1990s, Management Accounting, 73, 8, $22-26$.

Vancil, R. (1978). Decentralization: Managerial Ambiguity by Design: A Financial Executives Research Foundation Study, Homewood, Illinois, Dow Jones-Irwin.

Vaysman, I. (1996). A Model of Cost-based Transfer Pricing, Review of Accounting Studies, 1, 73-108. http://dx.doi.org/10.1007/BF00565413

Wagenhofer, A. (1994). Transfer pricing under asymmetric information: An evaluation of alternative methods. European Accounting Review, 3(1), 71-103. http://dx.doi.org/10.1080/09638189400000004

Wei, D. (2004). Inter-departmental cost allocation and investment incentives. Review of Accounting Studies. 9, 97-116. http://dx.doi.org/10.1023/B:RAST.0000013630.18838.04

Zimmerman, J. (1979). The Costs and Benefits of Cost Allocation. The Accounting Review, 504-521.

Zimmerman, J. (1997). Accounting for Decision Making and Control (2nd Ed.). Irwin/McGraw-Hill.

\section{Notes}

Note 1. In their survey of the thousand largest manufacturing companies in America, (Reece and Cool, 1978) find that $98.5 \%$ were organized in a multi-profit center form. Similarly, (Vancil,1978) finds that of the 313respondents in his study of manufacturing firms, 296 (or about 95\%) had two or more profit centers.

Note 2. (Merchant, 1989) concludes from a study of 203 profit centers that virtually all contracts for profit center managers are based on divisional income.

Note 3. According to (Horngren, Sundem and Stratton, 2006), the percent of direct costs for most companies is less than $50 \%$. For the rest of the costs, the choice is either to apply a cost allocation method or leave them unallocated.

Note 4. By cost allocation, I refer to the spreading of costs across products. This paper does not address inter-temporal cost allocation, which is allocation across periods.

Note 5. In 1982, Govindarajan and Anthony (G \& A) surveyed 1,000 large companies, finding that most large companies price their products based on full cost (i.e..variable costs plus allocated fixed costs.) In 1995, Shim and Sudit conducted a similar survey of pricing practices in U.S. manufacturing companiesand showed that full-cost pricing dominated pricing practices $(69.5 \%)$. Moreover, most of the responding companies $(91 \%)$ were in the multi-products environment, averaging 75 products.

Note 6. See for example, (Zimmerman, 1997), (Horngren et al., 2012) and (Datar, Rajan, and Rajan, 2014). These textbooks cite four reasons for allocating costs: First, allocation is required for valuing inventories and for computing income as per the generally accepted accounting principles. Second, allocations help managers in better understanding the "true" costs of a particular product or service, thereby leading to better economic decisions making relating to pricing and resource planning. Third, allocations help managers in inducing desired organizational behavior and promoting goal congruence. Finally, they help in performance evaluation of divisional managers in large, decentralized companies

Note 7. According to (Zimmerman, 1979), “ Usually cost allocations are discussed within the context of inventory costing and pricing decisions. However, the allocation problem also arises under the guise of transfer pricing, divisional performance evaluation and line of business reporting".

Note 8. The paper excludes negotiated and market-based TP for several reasons: first, they are not as widely used as CTP; negotiated TP is difficult to analyze due to costs of conflict that are not easily quantified (see (Eccles1985) for a strong case against negotiated TP) while market-based TP policies are usually infeasible simply because there is no 
easily identified market price for the good in question; (Shelanski, 1994) notes that for about $90 \%$ of the products in his study, there was no ready market; finally, CTP appears to be a rich enough domain to offer interesting comparisons among alternative policies.

Note 9. A survey by (Ernst and Young, 2005) indicates that 57 percent of the firms studied use a cost based method for transfer of intangible goods.. See also (Ernst and Young, 2008).

Note 10. According to (Vancil, 1978), roughly half of the firms using cost-based TP use actual cost-based TP and the other half use standard cost-based TP.

Note 11. Although the percentages may vary depending on the type of industry, a typical example is Harley Davidson, where $36 \%$ of the total production cost is classified as manufacturing overhead. (See (Horngren, Datar and Foster, 2012)).

Note 12. Industries in which single processes simultaneously yield multiple products abound: agriculture, extractive and chemical industries, and the semiconductor industry, to name a few. In many cases, no single product can be produced without accompanying products appearing.

Note 13. See for example, (Balakrishnan and Sivaramakrishnan, 2002) who discuss four cost allocation systems: traditional volume based systems, activity based costing systems, tome driven activity based costing systems, and resource consumption accounting.

Note 14. Due to these reasons perhaps, ACTP is extremely popular in the industry. For example, Tang's (1992) survey of transfer pricing methods used by Fortune 500 companies shows that $46.2 \%$ of them use cost-based methods for domestic transfers. Approximately half of these companies use policies that are based on actual cost.

Note 15. Other papers on transfer pricing that adopt an incomplete contracting framework include (Holmstrom and Tirole, 1991), (Wagenhofer, 1994), (Edlin and Reichelstein, 1995), (Baldenius, 2000), (Vaysman, 1996), (Dikolli and Vaysman, 2006) and (Pfeiffer, Schiller, and Wagner 2011).

Note 16. (Tang, 1992) provides empirical evidence of the transfer pricing methods used by firms. He reports that of the transfer price methods used by 143 Fortune 500 firms, 46.2 percent are cost based. Of these, only 7.7 percent use variable costs of production, 53.8 percent use full production costs; and 38.5 percent use full production cost plus a mark up or subsidy.

Note 17. Cost control, profit evaluation, accountability, cost control and motivation have been cited as reasons for cost allocation.

Note 18. See for example, (Baldenius, 2003), (Baldenius, Dutta and Reichelstein, 2007), (Rogerson, 1997, 2008), (Rajan and Reichelstein, 2009)

Note 19. Manufacturing overhead can be a significant number for many companies. (Miller and Vollman, 1985) mentioned that overhead cost as a percentage of overall manufacturing cost have been rising steadily as direct labor costs to value added had declined. Data suggest that manufacturing overhead averages $35 \%$ of production in the United States and 26\% in Japan.

Note 20. Without this assumption Good 2 would either not be produced at all or would be produced in all situations, rendering the allocation problem trivial.

Note 21. For example, in a detailed case analysis of the standard-setting process, (Eccles and White 1988) quote a senior executive: "It is here that games can really be played. [Standard costs] should have been reviewed by the corporate controller and corporate vice-president for manufacturing. As it was, they were determined by the general manager of [the selling division]" (p. S28.) 


\section{Proof of Proposition 1:}

Define:

$$
\varphi(y)=y+\frac{F_{1}}{f_{1}}(y)
$$

From our assumption on the slope of the hazard rate, we see that $\phi($.$) is increasing and hence invertible.$

Lemma 1. The standard cost reported in SCTP by a production manager of type $\theta_{2}$ is given by $S\left(\theta_{2}\right)=R_{1}^{*}-\phi^{-1}\left(R_{1}^{*}+R_{2}^{*}-M-p\left(L_{1}^{*}+\theta_{2}+L_{2}^{*}\right)\right)$.

Proof: First-order maximization of the objective function (3.1)

Since $\phi(y)>y, \quad S\left(\theta_{2}\right)>M+p\left(L_{1}^{*}+\theta_{2}+L_{2}^{*}\right)-R_{2}^{*}$. This is the standard report that would induce the first-best production order from Division 1.

\section{Proof of Proposition 2:}

By (4.3), we are guaranteed that Good 2 is produced if and only if the order is received for Good 1.

If the order is placed $(q=1)$, Division 2 solves the following program (P1):

$$
\max _{L_{1}, L_{2}} \operatorname{Pr}\left[q^{*}=1 \mid A_{1}\right] *\left(R_{2}^{*}-A_{2}\right)
$$

subject to :

$$
\begin{aligned}
& \text { (1) } L_{2} \geq L_{2}^{*} \\
& \text { (2) } L_{1} \geq L_{1}^{*}+\theta_{2} \\
& \text { (3) } A_{j}=p L_{j}+\frac{L_{j}}{L_{1}+L_{2}} M
\end{aligned}
$$

The marketing manager's strategy regarding the final decision implies that:

$$
\operatorname{Pr}\left[q^{*}=1 \mid A_{1}\right]= \begin{cases}1 & \text { if } A_{1} \leq S \\ \mathrm{~F}\left(\mathrm{R}_{1}^{*}-A_{1} \mid q=1\right) & \text { if } A_{1}>S\end{cases}
$$

Definition 1. A plan for Division 2 is a triple $\left(S, L_{1}, L_{2}\right)$ which stipulates the standard cost to be reported at Step 3 and the labor units to be employed in production at Step 5 if the order is received from Division 1 at Step 4. (Note 1) Definition 2. An expensive plan is a plan $\left(S, L_{1}, L_{2}\right)$ for which $A_{1}\left(L_{1}, L_{2}\right)>S$. An inexpensive plan is a plan for which $A_{1}\left(L_{1}, L_{2}\right)<S$. An exact plan is a plan for which $A_{1}\left(L_{1}, L_{2}\right)=S$.

Lemma 2. An inexpensive plan cannot be optimal for Division 2.

Proof: For any choice of $\left(L_{1}, L_{2}\right)$ that induces $A_{1}<S$, sale of Good 1 is certain. Hence, the optimal choice among such $\left(L_{1}, L_{2}\right)$ is given by the solution to:

$$
\max _{L_{1}, L_{2}} R_{2}^{*}-A_{2}
$$

subject to :

$$
\begin{aligned}
& \text { (1) } L_{2} \geq L_{2}^{*} \\
& \text { (2) } L_{1} \geq L_{1}^{*}+\theta_{2} \\
& \text { (3) } A_{j}=p L_{j}+\frac{L_{j}}{L_{1}+L_{2}} M
\end{aligned}
$$

$$
\text { (4) } A_{1} \leq S
$$

Consider any feasible choice of $\left(L_{1}, L_{2}\right)$ (satisfying (1) and (2)) for which (4) holds with strict inequality. Since $\partial A_{2} / \partial L_{1}=-M L_{2} /\left(L_{1}+L_{2}\right)^{2}<0$ and since $A_{1}\left(L_{1}, L_{2}\right)$ is continuously differentiable in $L_{1}$, we can find a small enough increment $\delta$ for $L_{1}$ so that $A_{1}\left(L_{1}+\delta, L_{2}\right) \leq S$ and simultaneously $A_{2}\left(L_{1}, L_{2}\right)>A_{2}\left(L_{1}+\delta, L_{2}\right)$. But then, $R_{2}^{*}-A_{2}\left(L_{1}, L_{2}\right)<R_{2}^{*}-A_{2}\left(L_{1}+\delta, L_{2}\right)$ showing that no such $\left(L_{1}\right.$, $L_{2}$ ) can be optimal. 
Before further analyzing the production manager's decisions at Step 5, we use the preceding lemma to characterize the marketing manager's Step 3 decision.

Lemma 3. Division 1 's optimal strategy at Step 3 is to place the order for Good 1 (choose $q=1)$ if and only if $R_{1}^{*}-\theta_{1} \geq S$.

Proof: Consider first the case $R_{1}^{*}-\theta_{1}<S$. From Lemma 2, we know that $A_{1} \geq S$ so that placing the order yields a divisional income of $R_{1}^{*}-\theta_{1}-A_{1} \leq R_{1}^{*}-\theta_{1}-S<0$. Hence, Division 1 would not place the order if $R_{1}^{*}-\theta_{1}<S$. Now suppose that $R_{1}^{*}-\theta_{1} \geq S$. Placing the order in this case will result in a divisional income of $\max \left\{R_{1}^{*}-\theta_{1}-A_{1}, 0\right\}$ since whenever $R_{1}^{*}-\theta_{1}-A_{1}<0$, we must have $A_{1}>S$ so that the order can always be canceled. Thus, placing the order is better than not placing it.

Definition 3. Let $\Pi\left(S, L_{1}, L_{2}\right)$ denote Division 2's expected divisional income from the plan $\left(S, L_{1}, L_{2}\right)$.

Lemma 3 allows us to explicitly compute $\Pi\left(S, L_{1}, L_{2}\right)$ for any plan. For an expensive plan,

$$
\begin{aligned}
\Pi\left(S, L_{1}, L_{2}\right) & =\operatorname{Pr}\left[R_{1}^{*}-\theta_{1}<S\right](0) \\
& +\operatorname{Pr}\left[S \leq R_{1}^{*}-\theta_{1}<A_{1}\left(L_{1}, L_{2}\right)\right]\left(R_{2}^{*}-M-p L_{1}-p L_{2}\right) \\
& +\operatorname{Pr}\left[R_{1}^{*}-\theta_{1} \geq A_{1}\left(L_{1}, L_{2}\right)\right]\left(R_{2}^{*}-A_{2}\left(L_{1}, L_{2}\right)\right)
\end{aligned}
$$

The first component of (4) corresponds to the case in which Good 1 is not ordered $(q=0)$, the second component to the case in which it is ordered but not purchased $\left(q=1, q^{*}=0\right)$, and the third component to the case in which it is ordered and purchased $\left(q=q^{*}=1\right)$.

Observe that the second case does not arise for an inexpensive or exact plan for which we have:

$$
\Pi\left(S, L_{1}, L_{2}\right)=\operatorname{Pr}\left[R_{1}^{*}-\theta_{1} \geq A_{1}\left(L_{1}, L_{2}\right)\right]\left(R_{2}^{*}-A_{2}\left(L_{1}, L_{2}\right)\right)
$$

Lemma 4. An expensive plan cannot be optimal for Division 2.

Proof: Consider an expensive plan $\left(S, L_{1}, L_{2}\right)$. We have:

$$
\begin{aligned}
\Pi\left(S, L_{1}, L_{2}\right) & <\operatorname{Pr}\left[R_{1}^{*}-\theta_{1} \geq A_{1}\left(L_{1}, L_{2}\right)\right]\left(R_{2}^{*}-A_{2}\left(L_{1}, L_{2}\right)\right) \\
& =\Pi\left(A_{1}\left(L_{1}, L_{2}\right), L_{1}, L_{2}\right)
\end{aligned}
$$

In other words, Division 2 is always better off reporting $A_{1}\left(L_{1}, L_{2}\right)$ as the standard cost if it plans to use $\left(L_{1}, L_{2}\right)$ in production

This result is based on the simple fact that if the selling division manager could be sure that Good 1 will not be purchased, he would rather not make it at all. By quoting a standard cost lower than the actual cost, he would receive the order from a larger range of buying division types. However, these orders would eventually be canceled leaving the seller worse off than if he hadn't received the order in the first place.

The proposition is an immediate consequence of Lemma 2 and Lemma 4

Proof of Proposition 3.

We derive a sequence of lemmas that establish the proposition, starting with the existence of an L-shaped production frontier.

Lemma 5. There is a cutoff value $A_{1}^{*}=\frac{L_{1}^{*}+\theta_{2}}{L_{1}^{*}+\theta_{2}+L_{2}^{*}} M+p\left(L_{1}^{*}+\theta_{2}\right)$ such that if Division 2 chooses a plan with actual cost $A_{1}$ the following relationships hold:

(1) If $A_{1}<A_{1}^{*}$ then $L_{1}=L_{1}^{*}+\theta_{2}$ and $L_{2}=L_{1}\left(\frac{M}{A_{1}-p L_{1}}-1\right)$.

(2) If $A_{1} \geq A_{1}^{*}$ then $L_{2}=L_{2}^{*}$ and $L_{1}=\frac{\sqrt{X^{2}+4 p A_{1} L_{2}^{*}}-X}{2 p}$ where $X=M+p L_{2}^{*}-A_{1}$.

Proof: Minimizing $A_{2}$ along the iso- $A_{1}$ curve for $v$ is equivalent to minimizing $L_{2} / L_{1}=M /\left(v-p L_{1}\right)-1$. This is achieved by minimizing $L_{1}$ subject to feasibility, i.e. by moving leftward along the curve until either the vertical (case 1) or the horizontal (case 2) frontier is reached. The length of the intercept at this point of intersection is 
obtained by solving the equation of the curve for the other labor input. Note that the cutoff point is the level of $A_{1}$ that would be observed if the production manager produces both goods efficiently.

According to this result, the production manager wastes $L_{1}\left(L_{2}\right)$ if he decides on $A_{1}>(<) A_{1}$ *.

Recall Definition 3 in the proof of Proposition 2, and consider the plan $\left(A_{1}\left(L_{1}, L_{2}\right), L_{1}, L_{2}\right)$ for some choice of $\left(L_{1}, L_{2}\right)$ on the frontier. We have:

$$
\Pi\left(A_{1}\left(L_{1}, L_{2}\right), L_{1}, L_{2}\right)=F_{1}\left(R_{1}^{*}-A_{1}\left(L_{1}, L_{2}\right)\right)\left(R_{2}^{*}-A_{2}\left(L_{1}, L_{2}\right)\right)
$$

We denote this expected divisional income by $\Pi\left(L_{1}, L_{2}\right)$ and its partial derivative with respect to $L_{j}$ by $\Pi_{j}\left(L_{1}, L_{2}\right)$.

\section{Lemma 6.}

Proof: We have:

$$
\begin{aligned}
& \Pi_{1}\left(L_{1}^{*}+\theta_{2}, L_{2}^{*}\right)>0 \Rightarrow \Pi_{2}\left(L_{1}^{*}+\theta_{2}, L_{2}\right)<0 \text { for all } L_{2}>L_{2}^{*} \\
& \Pi_{1}\left(L_{1}^{*}+\theta_{2}, L_{2}^{*}\right)<0 \Rightarrow \Pi_{1}\left(L_{1}, L_{2}^{*}\right)<0 \text { for all } L_{1}>L_{1}^{*}+\theta_{2} \\
& \Pi_{2}\left(L_{1}^{*}+\theta_{2}, L_{2}^{*}\right)>0 \Rightarrow \Pi_{1}\left(L_{1}, L_{2}^{*}\right)<0 \text { for all } L_{1}>L_{1}^{*}+\theta_{2} \\
& \Pi_{2}\left(L_{1}^{*}+\theta_{2}, L_{2}^{*}\right)<0 \Rightarrow \Pi_{2}\left(L_{1}^{*}+\theta_{2}, L_{2}^{*}\right)<0 \text { for all } L_{2}>L_{2}^{*}
\end{aligned}
$$

and:

$$
\begin{aligned}
\Pi_{1}\left(L_{1}, L_{2}\right) & =-f_{1}\left(R_{1}^{*}-A_{1}\left(L_{1}, L_{2}\right)\right)\left(p+\frac{M L_{2}}{\left(L_{1}+L_{2}\right)^{2}}\right)\left(R_{2}^{*}-A_{2}\left(L_{1}, L_{2}\right)\right) \\
& +F_{1}\left(R_{1}^{*}-A_{1}\left(L_{1}, L_{2}\right)\right) \frac{M L_{2}}{\left(L_{1}+L_{2}\right)^{2}}
\end{aligned}
$$

(a) Let $k=L_{1}^{*}+\theta_{2}$. We need to show that for all $L_{2} \geq L_{2}^{*}$,

$$
\begin{aligned}
\frac{F_{1}}{f_{1}}\left(R_{1}^{*}-A_{1}\left(k, L_{2}\right)\right)> & \frac{\frac{M k}{\left(k+L_{2}\right)^{2}}\left(R_{2}^{*}-A_{2}\left(k, L_{2}\right)\right)}{p+\frac{M k}{\left(k+L_{2}\right)^{2}}} \\
& =\frac{R_{2}^{*}-A_{2}\left(k, L_{2}\right)}{1+\frac{p\left(k+L_{2}\right)^{2}}{M k}}
\end{aligned}
$$

Since $A_{1}\left(k, L_{2}\right)$ is decreasing in $L_{2}, F_{1} / f_{1}\left(R_{1}^{*}-A_{1}\left(k, L_{2}\right)\right)$ is increasing in $L_{2}$; also, since $A_{2}\left(k, L_{2}\right)$ is increasing in $L_{2}$, the right hand side of the inequality above is decreasing in $L_{2}$. It suffices, therefore, to show that the inequality holds for $L_{2}=L_{2}{ }^{*}$. But the antecedent $\Pi_{1}\left(k, L_{2}^{*}\right)>0$ is equivalent to: 


$$
\begin{aligned}
\frac{F_{1}}{f_{1}}\left(R_{1}^{*}-A_{1}\left(k, L_{2}^{*}\right)\right)> & \frac{p+\frac{M L_{2}^{*}}{\left(k+L_{2}^{*}\right)^{2}}}{\frac{M L_{2}^{*}}{\left(k+L_{2}^{*}\right)^{2}}}\left(R_{2}^{*}-A_{2}\left(k, L_{2}\right)\right) \\
& =\left(R_{2}^{*}-A_{2}\left(k, L_{2}\right)\right)\left(1+\frac{p\left(k+L_{2}^{*}\right)^{2}}{M L_{2}^{*}}\right)
\end{aligned}
$$

as required.

(b) We need to show that for all $L_{1} \geq k$,

$$
\frac{F_{1}}{f_{1}}\left(R_{1}^{*}-A_{1}\left(L_{1}, L_{2}^{*}\right)\right)<\frac{p+\frac{M L_{2}^{*}}{\left(L_{1}+L_{2}^{*}\right)^{2}}}{\frac{M L_{2}^{*}}{\left(L_{1}+L_{2}^{*}\right)^{2}}}\left(R_{2}^{*}-A_{2}\left(L_{1}, L_{2}^{*}\right)\right)
$$

Again, the LHS is decreasing in $L_{1}$ while the RHS is increasing in $L_{1}$. Hence, it suffices to show that the inequality holds at $L_{1}=k$. But this is exactly the condition in the antecedent.

The proofs of (c) and (d) are analogous to those of (a) and (b) and are omitted

Lemma 7. Exactly one of the following holds in ACTP:

1. $\Pi_{1}\left(L_{1}^{*}+\theta_{2}, L_{2}^{*}\right)>0$ : the optimal solution wastes labor on Good 1 .

2. $\Pi_{2}\left(L_{1}^{*}+\theta_{2}, L_{2}^{*}\right)>0$ : the optimal solution wastes labor on Good 2 .

3. $\Pi_{1}\left(L_{1}^{*}+\theta_{2}, L_{2}^{*}\right)<0$ and $\Pi_{2}\left(L_{1}^{*}+\theta_{2}, L_{2}^{*}\right)<0$ : the optimal solution is efficient.

Proof: (1) is implied by Lemma 6(a), (2) by 6(c) and (3) by 6(b) and 6(d). That (a) and (c) cannot hold together follows from the observation that the former requires:

$$
\frac{F_{1}}{f_{1}}\left(R_{1}^{*}-A_{1}\left(k, L_{2}^{*}\right)\right)>\left(R_{2}^{*}-A_{2}\left(k, L_{2}^{*}\right)\right)
$$

while the latter requires:

$$
\frac{F_{1}}{f_{1}}\left(R_{1}^{*}-A_{1}\left(k, L_{2}^{*}\right)\right)<\left(R_{2}^{*}-A_{2}\left(k, L_{2}^{*}\right)\right)
$$

Lemma 8. Suppose that $\frac{\partial \Pi}{\partial L_{1}}\left(L_{1}^{*}, L_{2}^{*}\right)>0$. Then there exists a critical value of $L_{1}=\lambda>L_{1}^{*}$ such that for $\theta_{2} \in\left[0, \lambda-L_{1}^{*}\right]$ the optimal production decision is $L_{1}=\lambda, L_{2}=L_{2}^{*}$. The value of $\lambda$ is given implicitly by the equation $\frac{\partial 1}{\partial L_{1}}\left(\lambda, L_{2}^{*}\right)=0$ i.e.

$$
\frac{F_{1}}{f_{1}}\left(R_{1}^{*}-p \lambda-M \frac{\lambda}{\lambda+L_{2}^{*}}\right)=\left(R_{2}^{*}-p L_{2}^{*}-M \frac{L_{2}^{*}}{\lambda+L_{2}^{*}}\right)\left(1+p \frac{\left(\lambda+L_{2}^{*}\right)^{2}}{M L_{2}^{*}}\right)
$$

Proof: Suppose that $\Pi_{1}\left(L_{1}^{*}+\theta_{2}, L_{2}^{*}\right)>0$ so that the best type of production manager chooses to waste labor on Good 1 , and let the optimal choice of $L_{1}$ made by this type be denoted by $\lambda$. Since all production possibilities feasible for a worse type are also feasible for the best type of production manager, it must be the case that any type for which $\lambda$ is feasible will make the same choice as the best type. Thus, all types $\theta_{2} \in\left[0, \lambda-L_{1}^{*}\right]$ choose to waste $L_{1}$ choosing the same level $\lambda$. The equation defining $\lambda$ is obtained by first-order maximization Lemma 9. ACTP results either in efficient production or in labor being wasted in the production of Good 1 at level $\lambda$. 
Proof: For $\theta_{2}>\lambda-L_{1}^{*}$, the choice $L_{1}=\lambda, L_{2}=L_{2}^{*}$ is infeasible. So these types will either produce efficiently or waste labor on the external good.

However, (4.5) rules out condition 2 in Lemma 7 so that labor is never wasted on the external good.

We complete the proof of the proposition by dividing it into two cases:

Consider first some value $\theta_{2}>\lambda-L_{1}^{*}$ for which, by Lemma 9, production is efficient. From (4.5) it follows that:

$$
\begin{aligned}
& \phi\left(R_{1}^{*}-p\left(L_{1}^{*}+\theta_{2}\right)-M \frac{L_{1}^{*}+\theta_{2}}{L_{1}^{*}+\theta_{2}+L_{2}^{*}}\right) \geq\left(R_{1}^{*}+R_{2}^{*}-p L_{2}^{*}-p\left(L_{1}^{*}+\theta_{2}\right)-M\right) \\
& \Leftrightarrow \phi^{-1}\left(R_{1}^{*}+R_{2}^{*}-p L_{2}^{*}-p\left(L_{1}^{*}+\theta_{2}\right)-M\right) \leq R_{1}^{*}-p\left(L_{1}^{*}+\theta_{2}\right)-M \frac{L_{1}^{*}+\theta_{2}}{L_{1}^{*}+\theta_{2}+L_{2}^{*}} \\
& \Leftrightarrow p\left(L_{1}^{*}+\theta_{2}\right)-M \frac{L_{1}^{*}+\theta_{2}}{L_{1}^{*}+\theta_{2}+L_{2}^{*}} \leq R_{1}^{*}-\phi^{-1}\left(R_{1}^{*}+R_{2}^{*}-p L_{2}^{*}-p\left(L_{1}^{*}+\theta_{2}\right)-M\right)
\end{aligned}
$$

Since the LHS represents the actual cost of (efficiently) producing Good 1 and the RHS the standard cost reported in SCTP, we have the result.

Now consider some value of $\theta_{2} \in\left[0, \lambda-L_{1}^{*}\right]$. The standard cost reported in ACTP by such a production manager is given by $S_{\lambda}=p \lambda+M \frac{\lambda}{\lambda+L_{2}^{*}}$. Since the standard cost reported in SCTP is increasing in $\theta_{2}$, it suffices to show that:

$$
\begin{aligned}
S_{\lambda} & \leq R_{1}^{*}-\phi^{-1}\left(R_{1}^{*}+R_{2}^{*}-p L_{2}^{*}-p L_{1}^{*}-M\right) \\
& \Leftrightarrow \phi\left(R_{1}^{*}-S_{\lambda}\right) \geq R_{1}^{*}+R_{2}^{*}-p L_{2}^{*}-p L_{1}^{*}-M \\
& \Leftrightarrow \frac{F_{1}}{f_{1}}\left(R_{1}^{*}-S_{\lambda}\right) \geq S_{\lambda}+R_{2}^{*}-p L_{2}^{*}-p L_{1}^{*}-M \\
& \Leftrightarrow\left(R_{2}^{*}-p L_{2}^{*}-M \frac{L_{2}^{*}}{\lambda+L_{2}^{*}}\right)\left(p \frac{\left(\lambda+L_{2}^{*}\right)^{2}}{M L_{2}^{*}}\right) \geq p\left(\lambda-L_{1}^{*}\right) \\
& \Leftrightarrow \frac{R_{2}^{*}-p L_{2}^{*}}{M}\left(\frac{\lambda+L_{2}^{*}}{L_{2}^{*}}\right)-1 \geq \frac{\lambda-L_{1}^{*}}{\lambda+L_{2}^{*}}
\end{aligned}
$$

Given our earlier assumption on $R_{2}^{*}$, we get that the LHS of the above inequality is at least $\frac{\lambda+L_{2}^{*}}{L_{1}^{*}+L_{2}^{*}}-1 \geq \frac{\lambda-L_{1}^{*}}{L_{1}^{*}+L_{2}^{*}}$, as required

Proof of Proposition 4: Since managers who produce efficiently report a lower standard in ACTP, we need only show that managers who waste labor on the internal good outperform SCTP as well:

$$
\begin{aligned}
& \iint_{\theta_{1}=0}^{R_{1}^{*}-S_{\lambda}}\left(R_{1}^{*}-\theta_{1}+R_{2}^{*}-M-p \lambda-p L_{2}^{*}\right) d F_{1} d F_{2} \\
& \geq \int_{\theta_{2}} \int_{\theta_{1}=0}^{R_{1}^{*}-S\left(\theta_{2}\right)}\left(R_{1}^{*}-\theta_{1}+R_{2}^{*}-M-p\left(L_{1}^{*}+\theta_{2}+L_{2}^{*}\right) d F_{1} d F_{2}\right.
\end{aligned}
$$

Since the upper limit of the inner integral as well as the value of the integrand in the RHS increase with a reduction in $\theta_{2}$, it suffices to show that the following inequality holds:

$$
\begin{gathered}
\int_{\theta_{1}=0}^{R_{1}^{*}-S_{\lambda}}\left(R_{1}^{*}-\theta_{1}+R_{2}^{*}-M-p \lambda-p L_{2}^{*}\right) d F_{1} \\
\geq \int_{\theta_{1}=0}^{R_{1}^{*} S_{0}}\left(R_{1}^{*}-\theta_{1}+R_{2}^{*}-M-p L_{1}^{*}-p L_{2}^{*}\right) d F_{1}
\end{gathered}
$$


where $S_{0}$ is the standard cost reported by $\theta_{2}=0$ in SCTP.

Lemma 10: Suppose that $\theta_{1}$ is uniformly distributed over the range $\left[0, R_{1}^{*}\right]$. Then the inequality (2) holds.

Proof: Direct substitution.

Proof of Proposition 5: As in the proof of Proposition 3, we derive a sequence of lemmas that establish the proof.

Given the hybrid transfer pricing scheme, after having set a standard cost of $S$, Division 2 faces the following problem at Date 5:

$$
\max { }_{L_{1}, L_{2}}\left\{R_{2}^{*}+\min \left\{A_{1}, S\right\}-A_{2}\left(L_{1}, L_{2}\right)-A_{1}\left(L_{1}, L_{2}\right)\right\}
$$

subject to:

$$
\begin{aligned}
& L_{1} \geq L_{1}^{*}+\theta_{2} \\
& L_{2} \geq L_{2}^{*}
\end{aligned}
$$

If the labor levels are chosen so that $A_{1} \leq S$ the objective function is:

$$
R_{2}^{*}-A_{2}\left(L_{1}, L_{2}\right)=R_{2}^{*}-p L_{2}-M \frac{L_{2}}{L_{1}+L_{2}}
$$

and otherwise it is:

$$
R_{2}^{*}-A_{2}\left(L_{1}, L_{2}\right)=R_{2}^{*}+S-p\left(L_{1}+L_{2}\right)-M
$$

Lemma 11: $L_{2}$ is never wasted in the hybrid scheme.

Proof: If $L_{2}>L_{2}^{*}$ and $A_{1}<S$, decreasing $L_{2}$ infinitesimally will preserve $A_{1}<S$ while increasing the value of (6.3) above; if $A_{1} \geq S$, decreasing $L_{2}$ infinitesimally will preserve $A_{1} \geq S$ while increasing the value of (3) above.

The seller's Date 5 problem can now be simplified to:

$$
\max _{L_{1}}\left\{R_{2}^{*}+\min \left\{A_{1}, S\right\}-A_{2}\left(L_{1}, L_{2}^{*}\right)-A_{1}\left(L_{1}, L_{2}^{*}\right)\right\}
$$

subject to:

$$
L_{1} \geq L_{1}^{*}+\theta_{2}
$$

Lemma 12: Let $S^{*}=p\left(L_{1}^{*}+\theta_{2}\right)+M\left(L_{1}^{*}+\theta_{2}\right) /\left(L_{1}^{*}+\theta_{2}+L_{2}^{*}\right)$ denote the standard cost corresponding to efficient production and truthful reporting. Then the following hold at Date 3:

1. if $S \leq S^{*}$ then $L_{1}=L_{1}^{*}+\theta_{2}$.

2. if $S>S^{*}$ then $L_{1}$ satisfies $S=p L_{1}+M L_{1} /\left(L_{1}+L_{2}^{*}\right)$.

Proof: In case (a), $A_{1} \geq S$ so that the TP will be $S$. The objective function is (6.4), which is maximized by choosing $L_{1}$ as small as possible. In case (b), if $L_{1}$ is chosen so that $A_{1} \geq S$, the objective function is maximized by minimizing $L_{1}$ as in (a); on the other hand, if $A_{1}<S$, the objective function is (2) which is maximized by maximizing $L_{1}$. In either case, the value of $L_{1}$ will be chosen to satisfy $S=p L_{1}+M L_{1} /\left(L_{1}+L_{2}^{*}\right)$

The buyer's Date 3 problem can now be solved:

Lemma 13: At Date 3 the internal good will be ordered iff $R_{1} \geq S$.

Proof: Lemma 12 implies that the transfer price will always be set to $S$, so that the marketing manager can expect to have a positive divisional income iff $R_{1} \geq S$

Let us now consider the standard announced at Date 2. Since the function $S\left(L_{1}\right)=p L_{1}+M L_{1} /\left(L_{1}+L_{2}^{*}\right)$ is invertible, we can think of a standard report $S$ equivalently as a report $L_{1}$. Using Lemma 12 and 13, we see that the seller's Date 1 problem is solved by the larger of the following programs:

$$
\max _{L_{1}>L_{1}^{*}+\theta_{2}} F_{1}\left(R_{1}^{*}-A_{1}\left(L_{1}, L_{2}^{*}\right)\right)\left(R_{2}^{*}-A_{2}\left(L_{1}, L_{2}^{*}\right)\right)
$$


and

$$
\max _{L_{1}>L_{1}^{*}+\theta_{2}} F_{1}\left(R_{1}^{*}-A_{1}\left(L_{1}, L_{2}^{*}\right)\right)\left(R_{2}^{*}+p L_{1}+M \frac{L_{1}}{L_{1}+L_{2}^{*}}-p\left(L_{1}^{*}+\theta_{2}\right)-p L_{2}^{*}-M\right)
$$

It is easily established that if the solution to (6) is in the interior, the solution to (5) must be at the boundary (and vice-versa). Noting that at $L_{1}=L_{1}^{*}+\theta_{2}$ the two objective functions are the same, we get the following result:

Lemma 14: Let $\lambda$ denote the unconstrained solution to (6) (i.e. without the constraint bounding $L_{1}$ from below.) Then the following characterizes the behavior of production managers in the hybrid scheme:

1. if $\lambda \geq L_{1}^{*}+\theta_{2}$ the standard reported will be $S_{\lambda}=p \lambda+M \lambda /\left(\lambda+L_{2}^{*}\right)$ and production will occur using $L_{1}=\lambda$.

2. if $\lambda<L_{1}^{*}+\theta_{2}$ production is efficient; if $F_{1} / f_{1}\left(R_{1}^{*}-A_{1}\left(L_{1}^{*}, L_{2}^{*}\right)\right) \leq R_{2}^{*}-A_{2}\left(L_{1}^{*}, L_{2}^{*}\right)$ the standard reported is exactly the same as that reported in SCTP; otherwise the standard reported is less than that reported in SCTP and exactly equal to the actual cost.

Notice that HCTP induces the same behavior as SCTP (case b) if $R_{1}^{*}$ is sufficiently small (the internal good is "secondary") and the same behavior as ACTP (case a) if $R_{1}^{*}$ is sufficiently large (the internal good is "primary"). For intermediate cases, HCTP does at least as well as SCTP and never worse than ACTP. This completes the proof.

\section{Notes}

Note 1. Note that the only difference between a complete strategy and a plan for Division 2 is that the former also includes the $\left(L_{1}, L_{2}\right)$ chosen if no order is placed at Step 4. Since, as just observed, the $\left(L_{1}, L_{2}\right)$ decision is trivial if only Good 2 is to be produced, we will not differentiate between Division 2's plans and complete strategies. 